\title{
PREGNANCY DIAGNOSIS TECHNIQUES IN GOATS - A REVIEW
}

\author{
M. KARADAEV \\ Department of Obstetrics, Reproduction and Reproductive Disorders, Faculty \\ of Veterinary Medicine, Trakia University, Stara Zagora, Bulgaria
}

\section{Summary}

Karadaev, M., 2015. Pregnancy diagnosis techniques in goats - a review. Bulg. J. Vet. Med., 18, No 3, 183-193.

Several techniques for pregnancy diagnosis in goats are developed. Some of them are efficient and applicable in the field, but not enough accurate. Others are outlined with a high precision, but require equipment and specialised skills. Laparoscopy, laparotomy and vaginal biopsy are accurate but invasive and thus, inappropriate for the routine practice. Abdominal inspection, transabdominal palpation and increased live weight could be indicative for pregnancy in goats but they are reliable only after the second half of gestation. Udder examination and palpation are of low accuracy and their independent application for pregnancy diagnosis is not suitable. Blood, milk and faecal progesterone assays could indicate pregnancy in goats after the $21^{\text {st }}$ post insemination day until the end of gestation. The detection of pregnancy associated glycoproteins (PAGs) in blood plasma or milk samples is an early pregnancy marker but requires laboratory equipment. Non-return to oestrus is a cheap, practical and widely used method for detection of pregnancy between post insemination days 17 and 21 and does without signs of oestrus are assumed to be pregnant. A-mode, B-mode and Doppler ultrasonography are alternative methods for pregnancy diagnosis. Their accuracy and practical application potential are different. The two-dimensional ultrasound is one of the most appropriate methods for pregnancy diagnosis in goats. The accuracy of the method is about $100 \%$ on post insemination day 25-30 using the transrectal approach, whereas via the transabdominal approach, this accuracy is attained between the $40^{\text {th }}$ and the $45^{\text {th }}$ day.

Key words: diagnostics, goats, pregnancy

Goats are seasonally polyoestrous animals. The beginning and duration of the breeding period depends on a number of climatic and physiological factors (latitude, climate, breed, production system). The average duration of the sexual cycle is 21 days and is determined by the interval between two successive ovulatory oestruses. The oestrus duration is about 36 $\mathrm{h}$, ranging between 24 and $48 \mathrm{~h}$ depending on the age, breed, season and presence of male breeder. The fertilisation occurs in oviduct ampullae several hours after the ovulation. The embryo reaches the uterus 4-5 days after conception and is implanted 18-22 days after the beginning of the oestrus. The average gestation period is 149 days, but it could vary among breeds by several days (Fatet et al., 2011). 
The pregnancy diagnosis in goats is essential for better efficacy and management of reproduction (Doize et al., 1997), providing information about conception rates after artificial insemination (Matsas, 2007), gestation course (Amer, 2010), time for drying-off and parturition date (Doize et al., 1997; Gonzalez et al., 2004). The separation of pregnant and nonpregnant does in different groups reduces the losses from abortions, stillbirths or giving birth to non-viable offspring and optimises labour, feed and medication costs (Wani et al., 1998). The utilisation of an accurate and easily applicable method for pregnancy diagnosis allows the timely repeated insemination, breeding or culling of non-pregnant animals (Amer, 2010).

A number of techniques for pregnancy diagnosis have been implemented (Table 1 ), some of them are efficient and applicable under field conditions, but not enough accurate, others are distinguished with a high precision, but require specialised equipment and working skills (Ishwar, 1995; Medan et al., 2004; Amer, 2010). A method, easy to perform, reliable, not expensive and with high accuracy is preferable. The selection of a method depends on the stage of gestation, method's precision and the available equipment at the farm (Gonzalez et al., 2004). From the point of view of their practical application potential, Karen et al. (2001) divide the methods for pregnancy diagnosis in goats to less practical (non-return to oestrus, transabdominal palpation, laparoscopy, laparotomy, palpation of the caudal uterine artery, rosette inhibition test) and widely used (radiography, rectoabdominal palpation, hormonal assays, assay of pregnancy proteins, ultrasonography).

So far, there is no universally accepted classification of methods for pregnancy

Table 1. Comparative evaluation of the different methods for pregnancy diagnosis in small ruminants

\begin{tabular}{|c|c|c|c|c|}
\hline $\begin{array}{l}\text { Method for preg- } \\
\text { nancy diagnosis }\end{array}$ & Species & $\begin{array}{l}\text { Gestation } \\
\text { days }\end{array}$ & Accuracy & Reference \\
\hline $\begin{array}{l}\text { Non-return to oes- } \\
\text { trus }\end{array}$ & Sheep and goats & $>17-21$ & not reliable & Lindsay, 1973 \\
\hline \multirow[t]{2}{*}{ Live weight increase } & Goats & 28 & not reliable & Wani, 1982 \\
\hline & Sheep & 120 & not reliable & Domanski \& Lipeska, 1966 \\
\hline $\begin{array}{l}\text { Laparotomy and } \\
\text { perineoscopy }\end{array}$ & Sheep and goats & $28-56$ & $97 \%$ & Lamond, 1963 \\
\hline Cervical palpation & Goats & - & - & Kutty, 1999 \\
\hline \multirow[t]{2}{*}{ Radiography } & \multirow[t]{2}{*}{ Goats } & $>80$ & $100 \%$ & West, 1986 \\
\hline & & $>70$ & $100 \%$ & Memon \& Out, 1980 \\
\hline \multirow{4}{*}{$\begin{array}{l}\text { Hormonal analysis. } \\
\text { (progesterone and } \\
\text { estrone sulfate as- } \\
\text { says) }\end{array}$} & \multirow[t]{4}{*}{ Sheep and goats } & \multirow[t]{4}{*}{$21-28$} & \multirow[t]{4}{*}{$80-100 \%$} & Murray \& Newstead, 1998 \\
\hline & & & & Refstal et al., 1991 \\
\hline & & & & Sousa et al., 1999 \\
\hline & & & & Medan et al., 2004 \\
\hline PAGs immunoassay & Goats & $25-26$ & - & Gonzales et al., 2004 \\
\hline \multirow[t]{4}{*}{ Ultrasonography } & \multirow[t]{4}{*}{ Goats } & $15-30$ & $100 \%$ & Medan et al., 2004 \\
\hline & & $20-25$ & $100 \%$ & Amer, 2008 \\
\hline & & 26 & $100 \%$ & Abdelghafar et al., 2010 \\
\hline & & $30-35$ & $100 \%$ & Omontese et al., 2012 \\
\hline
\end{tabular}


diagnosis in goats. Therefore, we believe that the existing classification in sheep could be applicable also to goats with several changes and additions. The methods of limited interest for the practice are the laparoscopy, laparotomy, vaginal biopsy, transabdominal palpation, abdominal inspection, udder evaluation and appearance of milk secretion, live weight increase, rectoabdominal method, method of Hulet, while more practical approaches include the non-return to oestrus, hormonal and pregnancy proteins assays, radiography and ultrasonography.

The purpose of the present review is to go over the main pregnancy diagnosis techniques in goats and to discuss in detail the methods most commonly used in the practice with emphasis on their advantages and weaknesses.

\section{LAPAROSCOPY, LAPAROTOMY, VAGINAL BIOPSY}

According to the studies of Phillippo et al. (1971) the precision of diagnosing early pregnancy in small ruminants through laparoscopy is $91 \%$, between the $17^{\text {th }}$ and the $28^{\text {th }}$ day after breeding. The method is invasive, requires time, special equipment and skilled personnel, which makes it inapplicable under field conditions.

The pregnancy in goats could be detected by paramedian laparotomy and direct palpation of the uterus. The method is complex, non-ergonomic, expensive, reduces the chances for future conception and therefore, is inappropriate for practical application (Cutten, 1979).

Vaginal biopsy is based on changes occurring in the vaginal epithelium during the pregnancy. The method is used for pregnancy diagnosis in sheep (Richardson, 1972). A disadvantage outlined by Ishwar (1995) is that it could not detect twin pregnancy. The method is not suitable under field conditions, is expensive and requires time for specimen processing (Memon \& Ott, 1980). No data about the use of this technique for pregnancy diagnosis in goats are available. Therefore, the three abovementioned techniques are accurate, but invasive and inapplicable in the practice (Goel \& Agrawal, 1992).

\section{ABDOMINAL INSPECTION AND PALPATION; LIVE WEIGHT MONITORING}

The inspection of the abdominal region, transabdominal palpation of the uterus and foetuses and body weight increase are techniques for pregnancy diagnosis in goats with a low precision, applicable only during the second half of gestation (Taverne \& Noakes, 2009). The live weight increase during pregnancy is rather variable, and therefore not enough reliable trait (Domanski \& Lipecka, 1966).

\section{UDDER EVALUATION AND MILK SECRETION INITIATION}

The udder development and the appearance of colostrum is also used as a method for detection of pregnancy. Between gestation days 111 and 130, a moderate development of the udder occurs in $96 \%$ of sheep, and after the $130^{\text {th }}$ day - a fully developed and enlarged udder is already observed in $84 \%$ of animals. The changes in udder consistency and its enlargement is an accurate and practical method for pregnancy diagnosis, but only by its end; moreover, it is consistent in primiparous ewes in which the udder development is more obvious (Watt et al., 1984). To the best of our knowledge, there are no reports about the applicability of this method in goats. 
Udder inspection and palpation are not accurate for pregnancy diagnosis in small ruminants and should not be used independently for this purpose; they should be better combined with other techniques (Das et al., 2011).

\section{RECTOABDOMINAL TECHNIQUE}

Rectal palpation, a routine technique for pregnancy diagnosis in large animals (cows and mares), is not pertinent to sheep and goats due to specific anatomic features (Ganaie et al., 2009). Kutty \& Sudarsanan (1996) have developed a technique for pregnancy detection in small ruminants by palpation with both hands. The method includes palpation of the uterus through the rectum with one hand, while the other presses the abdominal wall. Pregnancy is diagnosed on the basis of cervical dilatation, altered position of the uterus, palpation of placentomes or parts of the foetus, asymmetry of uterine horns and impossibility for palpation of ovaries (Kutty, 1999).

\section{HULET ROD METHOD}

In small ruminants, pregnancy could be detected by careful passing a lubricated glass rod ( $1.5 \mathrm{~cm}$ diameter, $50 \mathrm{~cm}$ length) into the rectum after preliminary fixation of the animal in dorsal recumbency. The rod is manipulated with one hand and the other exerts a moderate pressure in the abdominal region, anterior to the udder. In non-pregnant animals, the tip of the rod is palpated through the abdominal wall (Hulet, 1972). Although the technique is easy, cheap and fast (150 animals per hour), it is not recommended in goats because of the risk for injury of rectal mucosa (Ott et al., 1981) and the low accuracy of the method in the beginning of the pregnancy (Chauhan et al., 1991).

\section{HORMONAL ASSAYS}

The assay of steroid hormone concentrations (progesterone, estrone sulfate) at a determined time after insemination/mating aids the early detection of pregnancy (Worsfold et al., 1986; Murray \& Newstead, 1988; Refstal et al., 1991; Sousa et al., 1999).

\section{Progesterone assay}

Various methods are used for analysis of blood, milk and faecal progesterone concentrations in small ruminants for evaluation of their endocrine status - immunoenzymatic (ELISA), radioimmune (RIA) and immunochemiluminescence analysis (Boscos et al., 2003; Gaafar et al., 2005; Capezzuto et al., 2009; Jack et al., 2012).

The analysis of blood plasma or serum progesterone is indicative for pregnancy after post insemination day 21 (Boscos et al., 2003; Medan et al., 2004; Capezzuto et al., 2009). Blood plasma concentrations $>1 \mathrm{ng} / \mathrm{mL}$ between days $15-17$ for nulliparous and days 18-22 in parous goats indicate pregnancy. The accuracy of the assay is $75-86 \%$ in pregnant and 90 $100 \%$ in non-pregnant goats (Dawson, 1999; Boscos et al., 2003; Khadiga et al., 2005)

Milk progesterone $\geq 10 \mathrm{ng} / \mathrm{mL}$ on days 22-26 after mating indicate pregnancy with accuracy $>86 \%$, whereas concentrations $\leq 10 \mathrm{ng} / \mathrm{mL}$ denote lack of pregnancy with up to $100 \%$ accuracy (Dawson, 1999). False negative results could be due to pseudopregnancy, uterine or ovarian damages (Holdsworth \& Davies, 1979).

Progesterone is mainly converted in the liver and excreted via the bile in faeces under the form of the water-soluble metabolite pregnandiol-3-glucuronide (IPD G) (Docke, 1994; Schwartzenberger et al., 1996). The experiments of Jack et al. 
(2012) with goats indicate that the accuracy of the method for distinguish pregnant from non-pregnant animals on the $19^{\text {th }}-20^{\text {th }}$ day after mating was $100 \%$.

\section{Estrone sulfate assay}

Estrone sulfate could be detected in blood plasma of goats and sheep about the $70^{\text {th }}$ gestation day with concentrations ranging between $0.1-0.7 \mathrm{ng} / \mathrm{mL}$, gradually increasing until 2 days before the parturition (Tsang, 1978). According to Murray \& Newstead (1988) the presence of estrone sulfate in milk confirms pregnancy with accuracy of $82 \%$ and lack of pregnancy in $93 \%$ of cases.

\section{ANALYSIS OF PREGNANCY ASSOCIATED PROTEINS}

The detection of pregnancy in goats could be done by immunological analysis of some specific proteins, such as the early pregnancy factor. Specific antigens are detected by radioimmunological (RIA) (Zoli et al., 1992) or immunoenzymatic (ELISA) techniques using monoclonal (Green et al., 2005) or polyclonal antibodies between the $5^{\text {th }}$ and $60^{\text {th }}$ gestation days (Friedrich \& Holtz, 2004; 2010).

\section{Pregnancy associated glycoproteins}

The detection of pregnancy associated glycoproteins (PAGs) in blood plasma or milk samples is a reliable method for early pregnancy diagnosis in goats (Batalha et al., 2011; Zamfirescu et al., 2011; Shahin et al., 2013). According to Gonzalez et al. (2004) detectable blood plasma PAGs concentrations in goats appear around the 25-26 day of gestation. Shahin et al. (2013) reported statistically significant differences in PAGs levels by the $21^{\text {st }}$ day post breeding between pregnant and nonpregnant goats. The presence of PAGs in milk samples is also a precise criterion for pregnancy after the $32^{\text {nd }}$ gestation day (Gonzalez et al., 2004).

\section{Pregnancy-specific protein B}

Pregnancy-specific protein B (PSPB) was first detected in bovine placenta (Butler et al., 1982), secreted by binuclear cells of the foetal trophectoderm (Eckblad et al., 1985). PSPB is established in sheep and goats and could be also serve for diagnosis of pregnancy (Bearden et al., 2004)

\section{NON-RETURN TO OESTRUS}

The non-return to oestrus is among the oldest and commonly used methods for pregnancy detection in small ruminants. it is not expensive, practical and yields information about pregnancy at a very early stage after the mating $\left(17^{\text {th }}-21^{\text {st }}\right.$ day) (Goel \& Agrawal, 1992). The non-return to oestrus evaluation is not recommended during the late breeding period and for animals, synchronised during the anoestrus (Memon \& Ott, 1980). Very often, pregnant goats also exhibit signs of oestrus (Taverne \& Noakes, 2009; Das et al., 2011), and the prevalence of early embryonic death in some herds is not small. Such animals could be hardly differentiated, even in the presence of a male breeder. That is why, the technique is not deemed reliable for detection of pregnancy in goats (Elmore, 1988).

\section{RADIOGRAPHY}

The radiography as a imaging method for pregnancy diagnosis is applicable after the $80^{\text {th }}$ day post breeding, when the foetal skeleton is mineralised and could be visualised (West, 1986). The earliest term for radiographic detection of pregnant goats is the $58^{\text {th }}$ day after insemination (Barker \& Cawley, 1967). According to the au- 
thors, the foetal skeleton is radiologically visible after the $65^{\text {th }}$ gestation day. The expensive equipment and potential risks for both the operator and the patient are substantial drawbacks limiting the application of the technique.

\section{ULTRASONOGRAPHY}

Ultrasonography as a method for monitoring of the reproduction status in small ruminants is becoming increasingly important and popular (Medan \& Abd ElAty, 2010; Erdogan, 2012). Now, Amode, B-mode and Doppler ultrasound equipment is used for pregnancy diagnosis in goats. Their accuracy and usefulness under field conditions is various (Goel \& Agrawal, 1992; Ishwar, 1995).

\section{A-mode ultrasonography}

The early attempts of using ultrasound in animal reproduction are associated with type A (amplitude-depth) ultrasound equipment (Medan \& Abd El-Aty, 2010). Their work principle is based on ultrasound wave reflection that determines the boundaries of organs filled with fluid, such as the pregnant uterus. The type A apparatuses possess a good sensitivity and specificity, exhibiting an accuracy of 80 $85 \%$ between the $60^{\text {th }}$ and $120^{\text {th }}$ post breeding days (Dawson, 2002), but the proportion of false positive diagnoses could be considerable when the urinary bladder is full or in some inflammatory uterine diseases (hydrometra, pyometra) (Haibel, 1990; Karen et al., 2001).

\section{Doppler ultrasonography}

Doppler ultrasound scanners detect pregnancy through investigation of blood circulation in the median uterine artery, umbilical artery and foetal heartbeats (Ott et al., 1981; Wani et al., 2003). The tech- nique is applicable after the $25^{\text {th }}$ day after mating via the transrectal approach, but provided that soft faeces are present, a higher percentage of false negative diagnosis could be obtained. Some researchers report that the accuracy of Doppler ultrasonography for detection of pregnancy via the transrectal or transcutaneous approach was higher during the second or third gestation months (Lindahl, 1971; Wani, 1981; Watt et al., 1984; Serin et al., 2010). After using Doppler ultrasonography for pregnancy detection in goats, Wani et al. (1998) reported accuracy of $100 \%, 100 \%$ and $72 \%$, for foetal heartbeats, umbilical artery and median uterine artery, respectively. According to Russel \& Goddard (1995), Doppler ultrasound was not appropriate as a technique for gestational age determination.

\section{B-mode (brightness) real-time ultrasonography}

In veterinary practice, ultrasonography was introduced in the 1980s for diagnosis of pregnancy at the earliest gestational stage (Buckrell et al., 1988; Davey, 1986; Haibel, 1990). B-mode (brightness) realtime ultrasonography is the most commonly used diagnostic imaging techniques for detection of pregnancy in small ruminants (Wani et al., 1998; Langfort, 2003; Kähn, 2004; Sousa et al., 2004; Gardon, 2005; Johnson, 2005; Yotov, 2007). It is a modern, non-invasive, rapid and accurate method for early detection of pregnancy in animals (Abdelghafar et al., 2007; Santos et al., 2007). The share of false positive diagnoses is small (Ganaie et al., 2009). An experienced operator could achieve an accuracy of 91-100\% (Romano \& Christians, 2008).

Hesselink \& Taverne (1994) were the first to report the use of diagnostic ultrasound to detect pregnancy in goats. Af- 
terwards, B-mode ultrasonography has been applied by numerous researchers (Doize et al., 1997; Martinez et al., 1998; Gonzalez et al., 2004; Amer et al., 2010; Omontese et al., 2012). It is a reliable method for early diagnosis of pregnancy (Medan et al., 2004; Gonzales-Bulnes et al., 2010).

In goats, the transabdominal and transrectal approaches are most frequently used. They could be performed in standing position, without sedation of the animal (Vinoles-Gil et al., 2010). The appropriate time for transabdominal ultrasonography is between post breeding days 40 45 and for transrectal examination - between post breeding days 25 and 30 (Georgiev et al., 2003; Buckrell, 1988; Mialot et al., 1991; Dawson, 2002). The accuracy could attain $100 \%$ with $3.5,5.0$, $7.5 \mathrm{MHz}$ transducers (linear, sector or convex probes) (Vinoles-Gil et al., 2010).

The main criteria for positive diagnosis of pregnancy in goats are the visualisation of anechoic cross sections of the uterine lumen (embryonic vesicle), embryo/foetus or placentomes in the amniotic fluid. Embryonic vesicles could be detected between the $21^{\text {st }}$ and $28^{\text {th }}$ days, whereas the embryo could be visualised by the $28-35$ gestation days using transrectal and transabdominal uterine scans respectively (Haibel, 1990; Hesselink \& Taverne, 1994; Martinez et al., 1998; Abdelghafar et al., 2010; Amer, 2010)

The pregnancy diagnosis in goats is a primary factor for improving the reproductive performance in herds and achieving high economic efficiency. During the years, multiple techniques for pregnancy detection in small ruminants have been developed. Each method has advantages and drawbacks. Some of them are invasive or of low accuracy hence of limited practical use. Others are precise but re- quire equipment and specialised skills. The practical implementation of userfriendly, accurate and non-invasive methods for pregnancy detection in goats compatible with animal welfare standards would result in optimisation of the reproductive performance.

\section{REFERENCES}

Abdelghafar, R. M., R. M. Ibrahim, S. M. Abdelharimi \& B. H. Ahmed, 2010. Sensitivity and specificity of real-time ultrasonography for pregnancy diagnosis and litter size in Saanen goats (Capra Hircus). In: Proceedings of the $14^{\text {th }}$ Scientific Congress of the Faculty of Veterinary Medicine, Assiut University, Egypt, pp. 392401.

Abdelghafar, R. M., A. O. Bakhiet \& B. H. Ahmed, 2007. B-mode real-time ultrasonography for pregnancy diagnosis and fetal number in Saanen goats. Journal of Animal and Veterinary Advances, 6, 702705.

Amer, H. A., 2010. Ultrasonographic assessment of early pregnancy diagnosis, fetometry and sex determination in goats. Animal Reproduction Science, 117, 226-231.

Barker, C. A. V. \& A. J. Cawley, 1967. Radiographic detection of fetal number in goats. Canadian Veterinary Journal, 8, 59-61.

Batalha, E. S., J. Sulon, J. R. Figueiredo, J. F. Beckers, C. J. B. Espeschit \& R. Martins, 2001. Plasma profile of pregnancy associated glycoprotein (PAG) in pregnant $\mathrm{Al}-$ pine goats using two radioimmunoassay (RIA) systems. Small Ruminant Research, 42, 111-118.

Bearden, H. J., J. W. Fuquay \& S. T. Willard, 2004. Applied Animal Reproduction, $6^{\text {th }}$ edn., Pearson Prentice Hall, Upper Saddle River, New Jersey, NY, U.S.A.

Boscos, C. M., F. C. Samartzi, A. G. Lymberopoulos, A. Stefanakis \& S. Belibasaki, 2003. Assessment of progesterone concen- 
tration using enzymeimmunoassay for early pregnancy diagnosis in sheep and goats. Reproduction in Domestic Animals, 38,170-174.

Buckrell, B. C., 1988. Application of ultrasonography in reproduction in sheep and goats. Theriogenology, 29, 71-84.

Butler, J. E., W. C. Hamilton, R. G. Sasser, C. A. Ruder, G. M. Hass \& R. R. Williams, 1982. Detection and partial characterization of two bovine pregnancy-specific proteins. Biology of Reproduction, 26, 925-933.

Capezzuto, A., M. O. M. Chelini, E. C. G. Felippe \& C. A. Olivera, 2009. Correlation between serum and fecal concentration of reproductive steroids throughout gestation in goats. Animal Reproduction Science, 103, 78-86.

Chauhan, F. S. \& M. A. Waziri, 1991. Evaluation of rectal-abdominal palpation technique and hormonal diagnosis of pregnancy in small ruminants. Indian Journal of Animal Reproduction, 12, 63-67.

Cutten, I. N., 1979. Immediate and long term effects of post mating laparotomy on the lambing performance of Merino ewes. In: Proceedings of the Australian Society of Animal Production, 8, p. 338.

Das, G. K., G. A. Khan \& M. Pande, 2011. Pregnancy diagnosis in small ruminants: An overview. Indian Journal of Small Ruminants, 17, 21-31.

Davey, C. G., 1986. An evaluation of pregnancy testing in sheep using a real time ultrasound scanner. The Australian Veterinary Journal, 63, 347-348.

Dawson, L. J., 1999. Pregnancy diagnosis in goats. In: Proceedings of the $14^{\text {th }}$ Annual Goat Field Day, Langston University, Langston, pp. 97-103.

Dawson, L. J., 2002. Pregnancy diagnosis in goats. In: Proceedings of the $17^{\text {th }}$ Annual Goat Field Day, Langston University, Langston, pp. 41-44.

Döcke, F., 1994. Keimdrusen. In: Veterinarmedicinische Endocrinologie, ed. F.
Döcke, Gustav Fisher Verlag, Jena, pp. 399-508.

Doize, F., D. Vaillancourt, H. Carabin \& D. Belanger, 1997. Determination of gestational age in sheep and goats transrectal ultrasonographic measurement of placentome. Theriogenology, 48, 449-460.

Domanski, A. \& C. Lipecka, 1966. Increase in body weight as a method for diagnosing pregnancy in ewes. Roczniki Nauk Rolniczych Seria B, 69-73.

Eckblad, W. P., R. G. Sasser, C. A. Ruder, P. Panlasigui, \& T. Kuczunski, 1985. Localization of pregnancy-specific protein B (PSPB) in bovine placental cells using glucose oxidise-anti-glucose oxidise immunohistochemical stain. Journal of Animal Science, 61, 149-150.

Elmore, R. G., 1988. Pregnancy diagnosis and parturition. In: Fertility and Infertility in Veterinary Practice, eds. J. A. Laing, W. J. B. Morgan \& W. C. Wagner, Bailliere Tindall, London, pp. 65-80.

Erdogan, G., 2012. Ultrasonic assessment during pregnancy in goats - a review. Reproduction in Domestic Animals, 47, 157163.

Ishwar, A. K., 1995. Pregnancy diagnosis in sheep and goat: A review. Small Ruminant Research, 17, 37-44.

Fatet, A., M. T. Pellicer-Rubio \& B. Leboeuf, 2011. Reproductive cycle of goats. Animal Reproduction Science, 124, 211-219.

Friedrich, M. \& W. Holtz, 2004. Establishment of an ELISA to assess PAGconcentrations in blood and milk of dairy cows. Reproduction, Abstract Series, 31, 21.

Friedrich, M. \& W. Holtz, 2010. Establishment of an ELISA for measuring bovine pregnancy-associated glycoprotein in serum or milk and its application for early pregnancy detection. Reproduction in Domestic Animals, 45, 142-146.

Gaafar, K. M., M. K. Gabr, D. F. Teleb, 2005. The hormonal profile during the estrous 
cycle and gestation in Damascus goats. Small Ruminant Research, 57, 85-93.

Ganaie, B. A., M. Z. Khan, R. Islam, D. M. Makhdoomi, S. Qureshi \& G. M. Wani, 2009. Evaluation of different techniques for pregnancy diagnosis in sheep. Small Ruminant Research, 85, 135-141.

Gardon, J., 2005. Ultrasonics in animal production. Albeitrar, 79, 6-16.

Georgiev, E., S. Yotov \& M. Dimitrov, 2003. Some aspects of ultrasound diagnostics of pregnancy in goats. In: Proceedings of International Scientific Conference, Stara Zagora, vol. Human Medicine, Veterinary Medicine, pp. 262-265.

Goel, A. K. \& K. P. Agrawal, 1992. A review of pregnancy diagnosis techniques in sheep and goats. Small Ruminant Research, 9, 255-264.

Gonzales-Bulnes, A., P. Pallares \& M. I. Vazquez, 2010. Ultrasonographic imaging in small ruminant reproduction. Reproduction in Domestic Animals, 45, 9-20.

Gonzalez, F., F. Cabrera, M. Batista, N. Rodriguez, D. Alamo, J. Sulon \& J. F. Beckers, 2004. A comparison of diagnosis of pregnancy in the goat via transrectal ultrasound scanning, progesterone and pregnancy associated glycoprotein assays. Theriogenology, 62, 1108-1115.

Green, J., T. Parks, M. Avalle, B. Telegu, A. McLain, A. Peterson, W. McMillan, N. Mathialagan, R. Hook, S. Xie \& R. M. Roberts, 2005. The establishment of an ELISA for the detection of pregnancyassociated glycoproteins (PAGs) in the serum of pregnant cows and heifers. Theriogenology, 63, 1481-1503.

Haibel, G. K., 1990. Use of ultrasonography in reproductive management of sheep and goats herds. Veterinary Clinics of North America, Food Animal Practice, 3, 597613.

Hesselink, J. W. \& M. A. M. Taverne, 1994. Ultrasonography of the uterus of the goat. The Veterinary Quarterly, 16, 41-45.
Holdsworth, R. J. \& J. Davies, 1979. Measurement of progesterone in goat's milk: An early pregnancy test. The Veterinary Record, 105, 535.

Hulet, C. V., 1972. A rectal-abdominal palpation technique for diagnosing pregnancy in the ewe. Journal of Animal Science, 35, 814-818.

Jack, A. M. M., C-C. Chang, H-I. Peh, \& J. PW. Chan, 2012. Fecal progesterone for monitoring reproductive status in dairy goats. Turkish Journal of Veterinary and Animal Sciences, 36, 566-572.

Johnson, L. W., 2005. Ultrasound pregnancy diagnosis in small ruminants. In: Proceedings of the North American Veterinary Conference, Large Animal, Orlando, Florida, USA, pp. 8-12; 304-305.

Kähn, W., 2004. Ultrasonography in sheep and goats. In: Veterinary Reproductive Ultrasonography, ed. W. Kähn, Schlütersche Verlagsgesellschaft, Hannover, pp. 187210.

Karen, A., P. Kovacsi, J. F. Beckers \& O. Szenci, 2001. Pregnancy diagnosis in sheep: Review of the most practical methods. Acta Veterinaria Brno, 70, 115-126.

Khadiga, M. G., K. G. Mohamed, F. T. Doaa, 2005. The hormonal profile during the estrous cycle and gestation in Damascus goats. Small Ruminant Research, 57, 85-93.

Kutty, C. I. \& V. Sudarsnan, 1996. Bimanual examination of reproductive organs of nanny goats. In: Proceedings of the $8^{\text {th }}$ Kerala Scientific Congress, pp. 113-114.

Kutty, C. I., 1999. Gynecological examination and pregnancy diagnosis in small ruminants using bimanual palpation technique: A review. Theriogenology, 51, 15551564.

Langfort, C., 2003. Management of breeding ewes on pregnancy scanning data. Wool Technology and Sheep Breeding, 51, 142 143.

Lindahl, I. L., 1971. Pregnancy diagnosis in the ewe by intrarectal Doppler. Journal of Animal Science, 32, 922-925. 
Martinez, M. F., P. Bosch \& R. A. Bosch, 1998. Determination of early pregnancy and embryonic growth in goats by transrectal ultrasound scanning. Theriogenology, 49, 1555-1565.

Matsas, D., 2007. Pregnancy diagnosis in goats. In: Current Therapy in Large Animal Theriogenology, eds. R. S. Youngquist \& W. R. Threlfall, Saunders, Philadelphia, pp. 547-554.

Medan, M. S. \& A. M. Abd El-Aty, 2010. Advances in ultrasonography and its application in domestic ruminants and other farm animals reproduction. Journal of $\mathrm{Ad}$ vanced Research, 1, 123-128.

Medan, M., G. Watanabe, G. Absy, K. Sasaki, S. Sharawy \& K. Taya, 2004. Early pregnancy diagnosis by means of ultrasonography as a method of improving reproductive efficiency in goats. Journal of Reproduction and Development, 50, 391-397.

Memon, M. A. \& R. S. Ott, 1980. Methods of pregnancy diagnosis in sheep and goats. Cornell Veterinarian, 70, 226-231.

Mialot, J. P., I. Levy, P. Emery, 1991. Echographie et gestion des troupeaux caprins. Recueil de Médecine Vétérinaire, 168, 399-406.

Murray, R. D. \& R. Newstead, 1988. Determination of steroid hormones in goat milk and plasma as an aid to pregnancy diagnosis using an ELISA. The Veterinary Record, 122, 158-161.

Omontese, B. O., P. I. Rekwot, I. U. Ate, J. S. Rwuaan, H. J. Makun, R. A. Mustapha \& M. Lawal, 2012. Use of ultrasonography for pregnancy diagnosis in Red Sokoto goats. Scientific Journal of Biological Sciences, 1, 101-106.

Ott, R. S., W. F. Braun, T. F. Lock, M. A. Memon \& J. L. Stowater, 1981. A comparison of intrarectal Doppler and rectal abdominal palpation for pregnancy testing in goats. Journal of American Veterinary Medical Association, 178, 730-731.

Phillipo, M., G. H. Swap, J. J. Robinson \& J. C. Gill, 1971. The diagnosis of pregnancy and estimation of foetal numbers in sheep by laparoscopy. Journal of Reproduction and Fertility, 27, 129-132.

Refstal, K. R., J. V. Martiuk, C. S. F. Williams \& R. F. Nachreiner, 1991. Concentration of estrone sulphate in peripheral serum of pregnant goats: relationship of gestational length, foetal number and the occurrence of foetal death in utero. Theriogenology, 36, 449-461.

Richardson, C., 1972. Diagnosis of pregnancy in the ewe by vaginal biopsy. British Veterinary Journal, 128, 316-329.

Romano, J. E. \& C. J. Christians, 2008. Early pregnancy diagnosis by transrectal ultrasonography in ewes. Small Ruminant Research, 77, 51-57.

Russel, A. J. F. \& P. J. Goddard, 1995. Small animal reproductive ultrasonography. In: Veterinary Ultrasonography, ed. P. G. Goddard, CAB International, Wallingford, pp. 257-274.

Shahin, M., M. Friedrich, M. Gauly, J. F. Beckers \& W. Holtz, 2013. Pregnancyassociated glycoprotein (PAG) pattern and pregnancy detection in Boer goats using an ELISA with different antisera. Small $R u$ minant Research, 113, 141-144.

Santos, C., I. Guido, I. Rabelo, S. Torrea, F. Lopes Junior, M. Freitas, P. Lima \& L. Oliveira, 2007. Determination of the genital tubercle migration period in Morada Nova sheep fetuses by ultrasonography. Reproduction in Domestic Animals, 42, 214-217.

Schwartzenberger, F., E. Möstl, R. Palme \& E. Bambergk, 1996. Fecal steroid analysis for non-invasive monitoring of reproductive status in farm, wild and zoo animals. Animal Reproduction Science, 42, 515-526.

Serin, G., O. Gokdal, T. Tarimcilar \& O. Atay, 2010. Umbilical artery Doppler sonography in Saanen goat fetuses during singleton and multiple pregnancies. Theriogenology, 74, 1082-1087.

Sousa, N. M., J. M. Garbayo, J. R. Figueiredo, J. Sulon, P. B. D. Goncalves \& J. F. Beckers, 1999. Pregnancy associated glycoprotein and progesterone profiles during preg- 
nancy and postpartum in native goats from the northeast of Brazil. Small Ruminant Research, 32, 137-147.

Sousa, N. M., F. Gonzales, A. Karen, B. El Amiri, J. Sulon, G. Baril, Y. Cognie, O. Szenci \& J. F. Beckers, 2004. Diagnostic et suivi de gestation chez la chèvre et la brebis. Rencontres Autour des Recherches sur les Ruminants, 11, 377-380.

Taverne, M. \& D. Noakes, 2009. Pregnancy and its diagnosis. In: Veterinary Reproduction and Obstetrics, eds. D. E. Noakes, T. J. Parkinson \& G. C. W. England, Saunders, Philadelphia, pp. 76-122.

Tsang, C. P. W., 1978. Plasma levels of estrone sulfate, free estrogens and progesterone in the pregnant ewe gestation. Theriogenology, 10, 97-110.

Vinoles-Gil, C., A. Gonzales-Bulnes, G. B. Martin, F. S. Zlatar \& S. Sale, 2010. Sheep and goats. In: Ruminant and Camelid Reproductive Ultrasonography, eds. L. DesCoteaux, J. Colloton, G. Gnemmi, WilleyBlackwell, Hong Kong, pp. 181-210.

Wani, M., M. Shabeena, K. Mirsa \& N. Mauyra, 2003. Pregnancy diagnosis in farm animals - a review. Indian Journal of Dairy Science, 56, 1-8.

Wani, N. A., G. M. Wani, A. M. Mufti \& M Z. Khan, 1998. Ultrasonic pregnancy diagnosis in gaddi goats. Small Ruminant Research, 29, 239-240.

Wani, G. M, 1981. Ultrasonic pregnancy diagnosis in sheep and goats: A review. World Review of Animal Production, 17, 43-48.

Watt, B. R., G. A. Anderson \& J. P. Campell, 1984. A comparison of six methods used for detecting pregnancy in sheep. The Australian Veterinary Journal, 61, 377-382.

West, D. M., 1986. Pregnancy diagnosis in the ewe. In: Current Therapy in Theriogeno- logy, ed. D. T. Morrow, Saunders, Philadelphia, pp. 850-852.

Worsfold, A. I., R. J. Chamings \& J. M Booth, 1986. Measurement of estrone sulphate in sheep plasma as a possible indicator of pregnancy and the number of viable fetuses present. British Veterinary Journal, 142, 195-197.

Yotov, S., 2007. Early pregnancy diagnostics and determination of offspring number and gender in sheep. PhD thesis, Stara Zagora.

Zamfirescu, S., A. Anghel, D. Nadolu \& N. Dobrin, 2011. Plasmatic profiles of pregnancy-associated glycoprotein and progesterone levels during early pregnancy in Carpathian goat. Annals of the Romanian Society for Cell Biology, 16, 50-53.

Zoli, A., L. Guilbaut, P. H. Delahaut, W. Benitez-Ortiz, J. F. Beckers, 1992. Radioimmunoassay of a bovine pregnancy-associated glycoprotein in serum: Its application for pregnancy diagnosis. Biology of Reproduction, 46, 83-92.

Paper received 27.06.2014; accepted for publication 21.11.2014

\section{Correspondence:}

Manol Karadaev

Department of Obstetrics, Reproduction and

Reproductive Disorders,

Faculty of Veterinary Medicine,

Trakia University,

6000 Stara Zagora, Bulgaria

e-mail:karadaev@abv.bg 